\title{
Skin and Soft Tissue Injuries in Congenital Vascular Malformations
}

\author{
Kyung-Bok Lee ${ }^{1}$ and Dong-Ik Kim ${ }^{2}$ \\ ${ }^{1}$ Department of Surgery, Seoul Medical Center \\ 2Division of Vascular Surgery, Samsung Medical \\ Center, Sungkyunkwan University \\ School of Medicine, Seoul \\ South Korea
}

\section{Introduction}

Congenital vascular malformation (CVM) refers to malformed vessels resulting from arrested development during various stages of embryogenesis and presents in about $1.5 \%$ of the population (Belov, 1989; Malan \& Pulionisi, 1965; Villavicencio et al, 2002). The CVMs may originate from multiple vascular systems, including arterial, venous, and lymphatic, and represent as either a predominant form (e.g., arterial malformation) or as a mixed condition (venolymphatic malformation). As such, CVM has various clinical manifestations depending on vascular structural architecture, involved site(s), and type of malformed vessels present. In general, most CVMs are sporadic, but some are heritable in an autosomal dominant fashion (Arneja \& Gosain, 2008). In spite of advances in the field of vascular biology, the pathogenesis, natural history, and treatment principles of CVMs have yet to be understood or developed.

Occasionally, CVMs can be confused with infantile hemangiomas (Figure 1). Even though both anomalies represent cutaneous vascular manifestations, their histologic findings and clinical courses are completely different. Most hemangiomas appear at birth, are self-limited, and resolve spontaneously before 12 years of age. However, CVMs may be identified at birth, progress during childhood, and never regress during the lifespan (Figure 1).

Clinical manifestations of the CVM are determined by its embryologic characteristics, especially the stage of embryogenesis in which development was arrested. Thus, it represents a wide range of clinical symptoms from a simple birthmark to a life-threatening condition (Lee, 2005). A small, localized venous malformation may cause a simple cosmetic problem such as a birthmark; however, a diffuse type of arteriovenous malformation in a major organ may result in a life-threatening condition, such as congestive heart failure, intractable bleeding, or airway obstruction, in addition to serious disfigurement.

Despite diagnostic advances over the last three decades, it is very difficult to diagnose the CVM for a sole physician because the CVM may involve multiple vascular systems and manifest variable clinical presentations. Therefore, multidisciplinary collaboration of physicians from special departments is necessary for accurate diagnosis and successful treatment of CVM. 

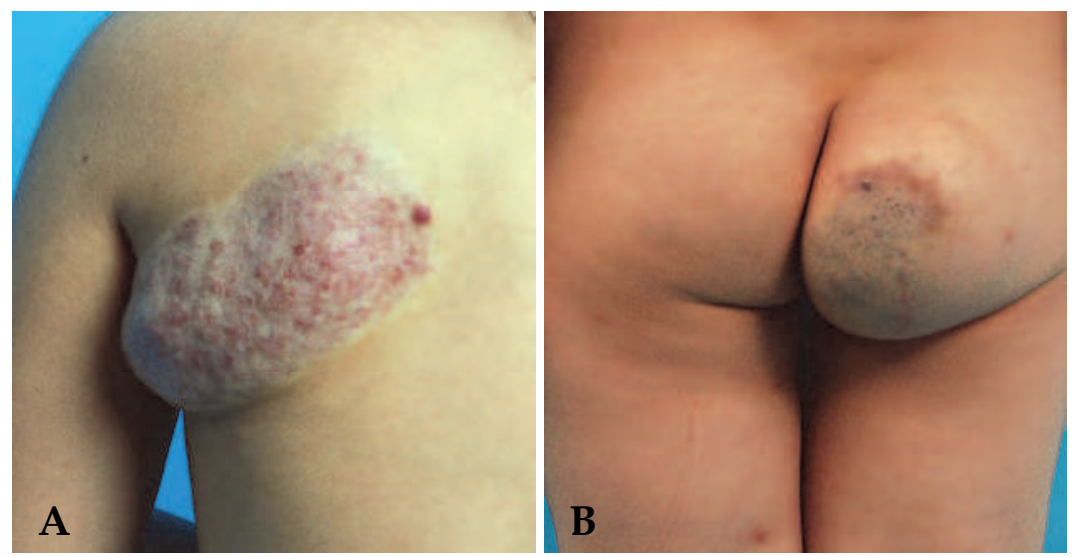

Fig. 1. Hemangioma and congenital vascular malformation. A, hemangioma in left back. B, venous malformation in right buttock.

Currently, complete excision of the nidus has been known as the only therapeutic modality for a cure of the CVM. However, complete surgical removal is nearly impossible because most CVMs are diffuse and of an infiltrative nature.

As an alternative treatment method, embolo/sclerotherapy may be an effective modality and successful in most CVMs, in particular the diffuse and infiltrative types. We previously reported that the incidence, the susceptible types, and the outcomes for skin and soft tissue injuries of embolo/sclerotherapy in CVMs (Lee et al., 2008).

This chapter reviews the general aspect of the CVMs and, based on our study, expands the incidence and treatment methods, including skin graft, in addition to the prognosis of skin and soft tissue injuries developed after embolo/sclerotherpay in patients with CVMs.

\section{Congenital vascular malformations: General aspect}

\subsection{Classification}

A proper classification of CVMs is very difficult since they develop as a result of arrest during various embryologic stages and represent a variety of clinical manifestations.

Over the centuries, various CVMs have been labeled with name-based eponyms, such as Klippel-Trenaunay or Parkes Weber syndromes. However, these eponyms were defined by only clinically relevant manifestations (e.g., birthmark, swelling, disfigurement) and did not identify the primary vascular lesion and/or other nonvascular anomalies. Although these old name-based eponyms have been replaced by new classifications based on anatomic and pathophysiologic status as well as clinically relevant manifestations, these are still valuable for understanding the cutaneous lesions of CVM, as well for the historical significance. For instance, Klippel-Trenaunay syndrome, which is characterized by cutaneous hemangiomas, soft tissue hypertrophy, and varicosities, can be replaced with hemolymphatic malformation in the Hamburg classification (Figure 2). However, as its historical eponym is well known, it can still be used to represent the cutaneous manifestations. 

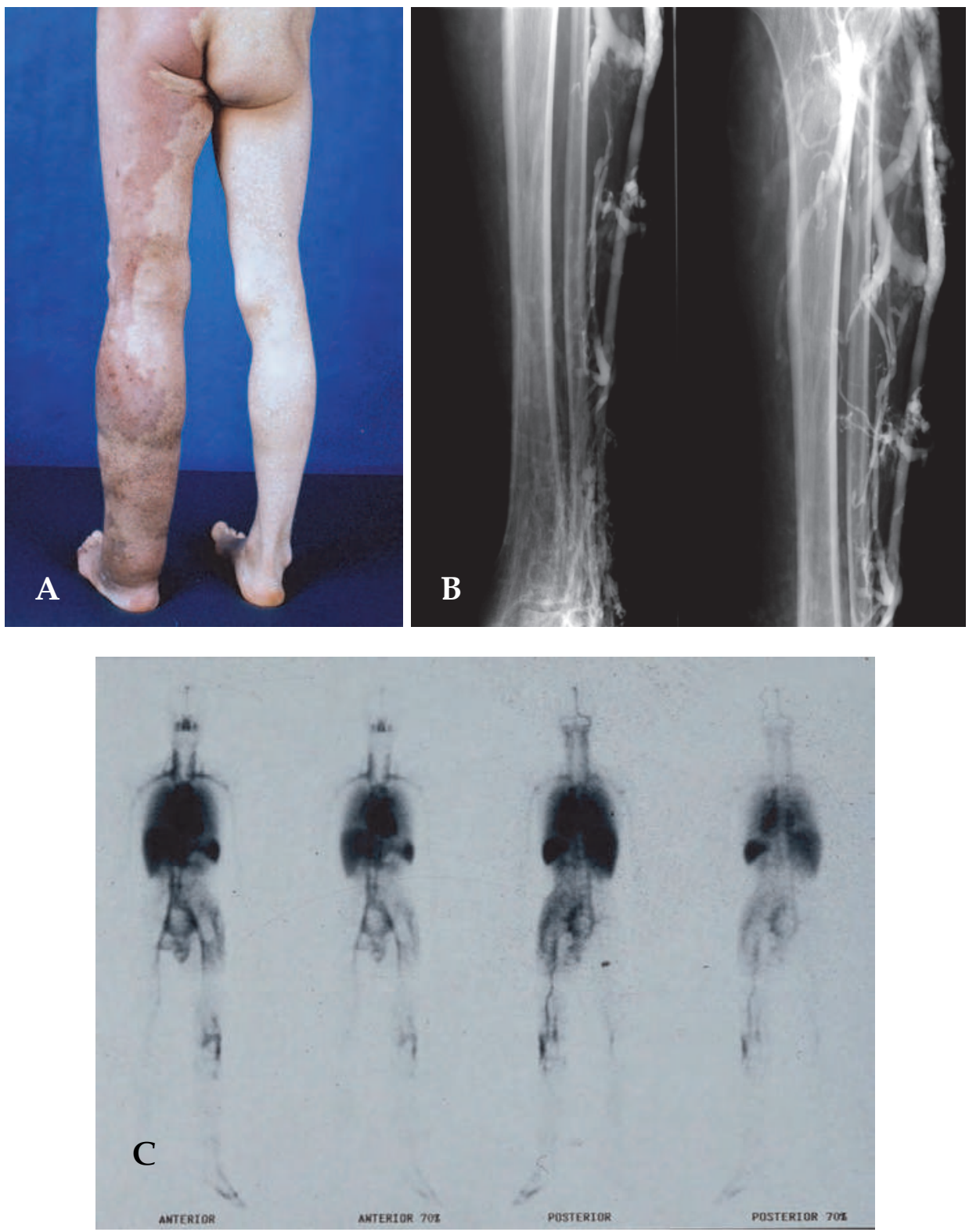

Fig. 2. Klippel-Trenaunay syndrome. A, Gross appearance. B, Ascending venogram. C, Whole body blood pool scan.

\subsubsection{Hamburg classification}

In 1988, the ISSVA (International Society for the Study of Vascular Anomalies) that was held in Hamburg, Germany, has adopted the new classification of CVMs based on the 
underlying anatomic, histologic, pathophysiologic, and hemodynamic status (Belov, 1989, 1990; Lee et al., 2007). This classification has been considered to be clinically applicable and is regarded as a modern system. In the Hamburg classification, CVMs are divided into five types based on the predominant vascular defect: arterial, venous, arteriovenous shunting, lymphatic, and combined (Table 1). Each type was subclassified into a truncal form and extratruncal form depending on the embryonic stage of developmental arrest (Lee, 2005). The initial classification system did not contain the capillary malformation, since their clinical significance had been considered uncertain. However, the addition of capillary malformation was subsequently proposed and supported.

\begin{tabular}{|c|c|}
\hline Types & Embyologic subtypes \\
\hline Predominantly arterial defects & $\begin{array}{l}\text { Truncular forms } \\
\text { Aplasia or obstruction } \\
\text { Dilatation } \\
\text { Extratruncular forms } \\
\text { Infiltrating } \\
\text { Limited }\end{array}$ \\
\hline Predominantly venous defects & $\begin{array}{l}\text { Truncular forms } \\
\text { Aplasia or obstruction } \\
\text { Dilatation } \\
\text { Extratruncular forms } \\
\text { Infiltrating } \\
\text { Limited }\end{array}$ \\
\hline Predominantly AV shunting defects & $\begin{array}{l}\text { Truncular forms } \\
\text { Deep } \\
\text { Superficial } \\
\text { Extratruncular forms } \\
\quad \text { Infiltrating } \\
\quad \text { Limited }\end{array}$ \\
\hline Predominantly lymphatic defects & $\begin{array}{l}\text { Truncular forms } \\
\text { Aplasia or obstruction } \\
\text { Dilatation } \\
\text { Extratruncular forms } \\
\text { Infiltrating } \\
\text { Limited }\end{array}$ \\
\hline Combined vascular defects & $\begin{array}{l}\text { Truncular forms } \\
\text { Arterial or venous } \\
\text { Hemolymphatic } \\
\text { Extratruncular forms } \\
\text { Infiltrating hemolymphatic } \\
\text { Limited hemolymphatic }\end{array}$ \\
\hline
\end{tabular}

Table 1. Hamburg classification for congenital vascular malformations (AV, arteriovenous)

Although the Hamburg classification is currently used worldwide and accepted in most clinical settings, further improvements in the CVM classification system will be needed to completely replace the old name-based eponyms. 


\subsubsection{Muliken classification}

The Muliken classification is a widely used alternative system which is based on the hemodynamic status of the CVM and also provides guidelines for clinical management (Mulliken, 1993; Mulliken \& Glowacki, 1982). In this classification, all CVMs are divided into two types depending on blood flow: fast-flow and slow-flow. It supplies a simple understanding for the complex nature of CVM and helps to determine whether treatment is needed, as well as treatment modality. Currently, the Muliken classification has been used in conjunction with the Hamburg classification in the clinical field.

\subsection{Pathophysiology}

\subsubsection{Extratruncular types}

Extratruncular CVMs present by arrest during early embryonic life while the vascular system is in the reticular stage (Bastide \& Lefebvre, 1989). As such, extratruncular CVMs contain the characteristics of mesenchymal cells and have proliferative potential. Therefore, all extratruncular CVMs show high risk for exacerbation or recurrence when stimulated or treated improperly and can infiltrate and invade the surrounding tissues and show a secondary impact, as well as the hemodynamic effect.

Almost all extratruncular CVMs present with mechanical and hemodynamic effects. For example, if the CVM is located in the neck, it may cause airway or esophageal obstruction due to the mechanical characteristics of CVM progression. Moreover, the hemodynamic effect, particularly the arteriovenous malformation of extratruncular CVM, may result in serious complications of the cardiovascular system because the arterial flow directly enters the venous drainage system without the resistance of the capillary system.

\subsubsection{Truncular type}

Truncular CVMs occur when developmental arrest happens later during the vascular trunk formation stage of embryonic development (Bastide \& Lefebvre, 1989). These CVMs have a significant risk for hemodynamic complications because the lesions lose their embryonic characteristics. If the truncular type of CVM is located in a lower extremity, it may show clinical manifestations of lymphedema or chronic venous insufficiency. In addition, if arteriovenous malformation presents as the truncular type, life-threatening cardiovascular complications, including congestive heart failure, could develop.

\subsection{Diagnosis}

It is impossible for one expert to diagnose the CVM because it has numerous clinical manifestations and various diagnostic modalities. For these reasons, a multidisciplinary team, composed of a vascular surgeon, a plastic and reconstructive surgeon, an orthopedic surgeon, a dermatologist, and an interventional radiologist, is needed to diagnose and classify the CVM. In addition to the diagnosis and classification, the CVM treatment plan must also be developed by the consensus of the multidisciplinary team.

\subsubsection{CVM versus hemangioma}

Both CVM and hemangioma are grouped as vascular anomalies; however, each anomaly presents with completely different behaviors (Lee, 2005).

By definition, a hemangioma is a vascular tumor that mainly appears at birth and is characterized by rapid growth and spontaneous regression. Hemangioma growth starts after birth, and spontaneous regression usually occurs before 12 years of age. In comparison 
to CVM, a rapidly growing hemangioma represents mature endothelium that shows normal mitotic activity.

In general, the differential diagnosis between CVM and hemangioma depends on the clinical manifestations and physical examinations. However, if a vascular lesion is the only diffuse mass located in the subcutaneous tissue or the muscle layer, diagnosis may be impossible and needs to be differentiated. Therefore, tissue confirmation is sometimes required in a specific case for the differential diagnosis.

\subsubsection{Clinical manifestations}

CVMs can show a wide range of clinical forms depending on the predominant type and location. Most capillary malformations may present as a port-wine stain and can appear anywhere in the body as a localized or extensive form. In addition, cutaneous manifestations of capillary malformations are associated with anomalies of the soft tissue or the skeletal system. For example, hypertrophy of soft tissue and leg bone is expressed with cutaneous manifestations in patients with Klippel-Trenaunay syndrome.

Venous malformations also may present at birth and can be distinctively compressed. Some venous malformations located in the skin and the subcutaneous layer of the face or neck may cause cosmetic problems, such as disfiguration or asymmetry. Venous malformation in the bone can cause a leg length discrepancy due to bone growth disturbances and pathologic fractures due to bone destruction. However, if the malformation is located near the airway, it has a potential life-threatening risk due to the secondary compression effect and intractable bleeding (Figure 3).

Most lymphatic malformations are asymptomatic except for skin manifestations. Lymphatic malformations present as a primary lymphedema (diffuse swelling) or a lymphangioma (localized swelling). Complicated lymphatic malformations may lead to non-vascular consequences rather than vascular complications, such as the compression of surrounding organs, pathologic fractures, or infection.

Arteriovenous malformations are often indistinct unless complications have developed. The direct fistulas between the arteries and the veins are formed in the lesion, and these fistulas are represented as the thrill and bruit. Arteriovenous malformation frequently manifests several serious complications, including distal ischemia and gangrene due to the shunt, intractable bleeding, or high-output cardiac failure.

\subsubsection{Non-invasive tests}

Clinical suspicion is most important for the diagnosis when the baby or child shows the skin manifestation or disfigurement. If a CVM is suspected, a detailed history and a physical examination are taken. In patients with suspected CVM, non-invasive tests, such as duplex ultrasonography, CT or MR angiography, or Tc-99m RBC whole body blood pool scintigraphy (WBBPS), can lead to a definite diagnosis in most circumstances.

Duplex ultrasonography can be examined initially because it provides excellent hemodynamic as well as anatomic information. CT or MR angiography shows the exact location and the relationship with adjacent tissue, the feeding artery, and the draining vein, so it helps to determine the treatment plan. WBBPS can detect another lesion in the body, assess the treatment efficacy, and rule out lymphatic malformation (Figure 4). In addition to these basic tests, if the patient has a leg-length discrepancy, a bone X-ray should be 
performed to rule out osseous CVM. When lymphatic malformation is suspected, radioisotope lymphoscintigraphy could be added. In arteriovenous malformation, transarterial lung perfusion scintigraphy can provide useful information for the general impact of an arteriovenous shunt.
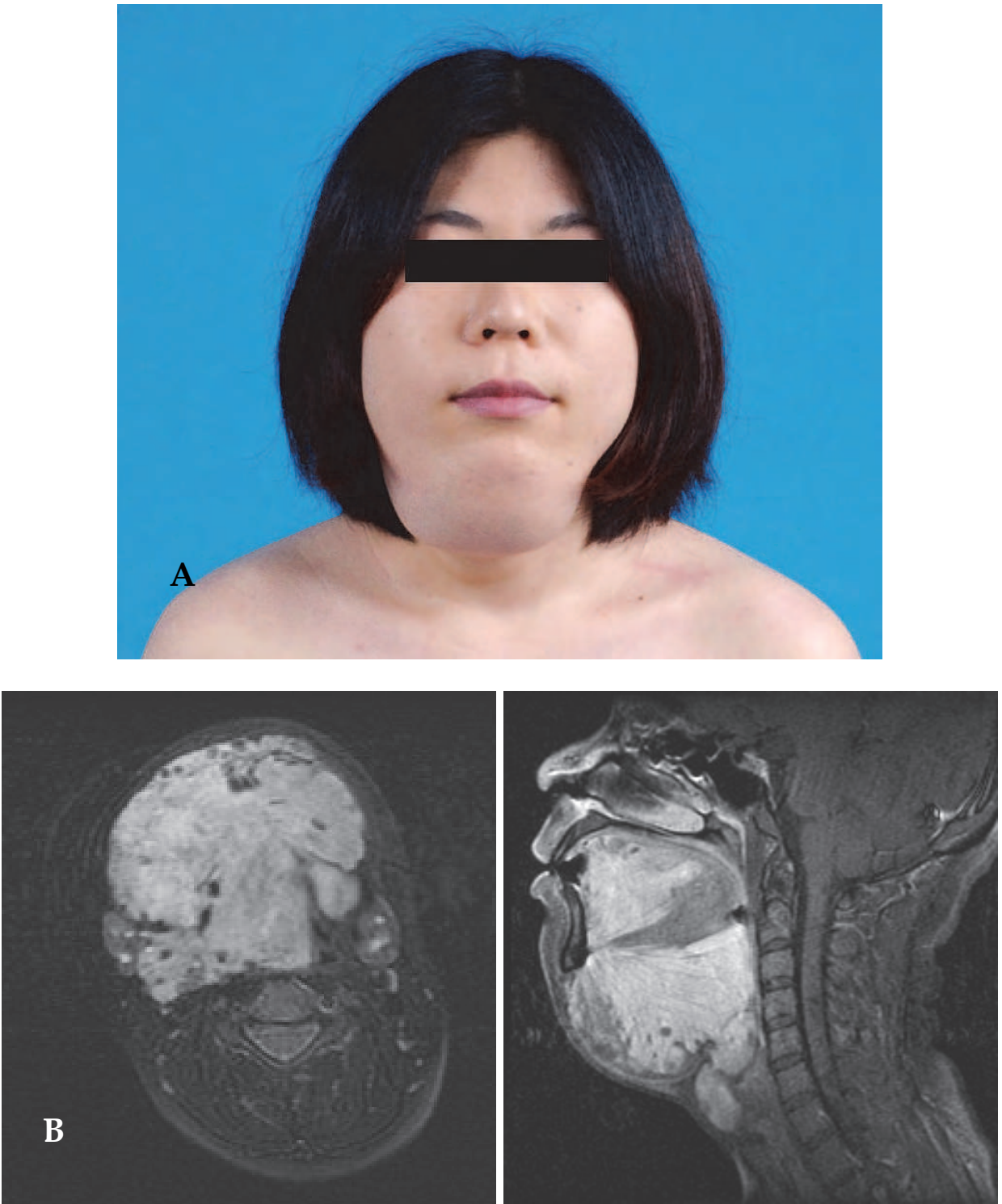

Fig. 3. Venous malformation affecting the airway A, Huge venous malformation presents as diffuse swelling below the chin. B, T2-weighted MRI images show the airway involvement of venous malformation. 

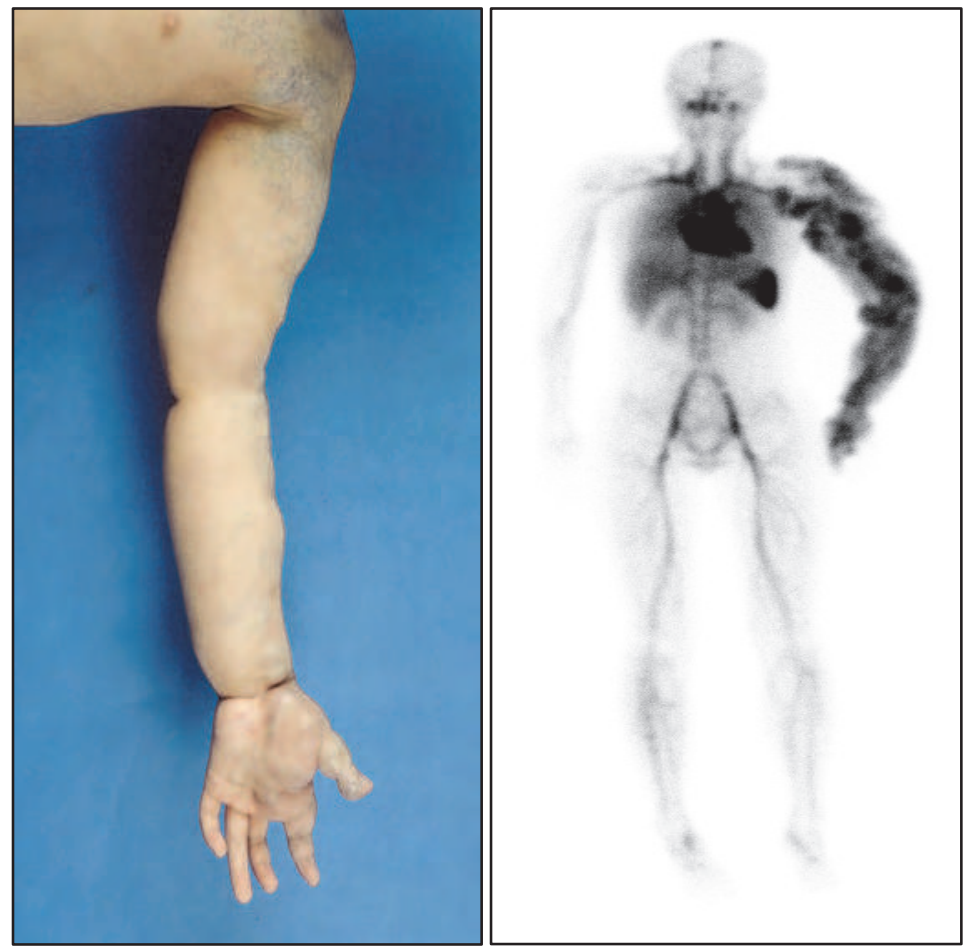

Fig. 4. Gross appearance and whole body blood pool scan of venous malformation involving entire arm.

\subsubsection{Invasive tests}

Currently, most invasive diagnostic tests have been replaced by noninvasive studies because the majority of CVMs can be definitely diagnosed by the latter. However, invasive tests, such as digital subtraction angiography and venography, remain as a standard and useful modality for diagnosing and determining the treatment plan.

A selective angiography provides a guideline for a treatment method in patients with arteriovenous malformations. A venography in conjunction with direct-puncture phlebography simultaneously enables the diagnosis and treatment in venous malformations. However, traditional percutaneous direct-puncture lymphangiography is rarely needed in patients with lymphatic malformations.

\subsection{Treatment}

Until the pathophysiology and biological behavior of CVMs had been characterized, most treatment approaches failed to relieve the hemodynamic consequences and secondary complications or to cure the CVM itself. Overaggressive treatment due to lack of knowledge about various CVMs have also contributed to poor clinical outcomes.

In the treatment of CVMs, the complete eradication of the nidus provides complete curability, but it is rarely possible because most CVMs are infiltrative and located in deeper and surgically inaccessible regions. 
Two decades ago, the Hamburg classification provided a better understanding of the anatomy, the pathophysiology, and hemodynamic status of CVMs. Based on this classification, new treatment approaches have been developed.

Previously, we proposed a multidisciplinary team approach composed of 15 clinical specialists for diagnosis and treatment. Surgeons and clinicians in vascular surgery, plastic and reconstructive surgery, pediatric surgery, interventional and diagnostic radiology, nuclear medicine, orthopedic surgery, head and neck surgery, oral-maxillary surgery, anesthesiology, vascular medicine, pathology, physical medicine and rehabilitation, psychiatry, and dermatology should all be represented (Lee, 2005). This team has been operated effectively by a 'referral system' to diagnose, develop a treatment plan, and manage the consequence after treatment.

All CVMs may not require treatment and a poorly planned treatment could awake the quiescent stage of CVM. In particular, aggressive treatment for CVM should be considered when the CVM is associated with symptoms such as hemorrhage, high-output heart failure, disabling pain, cosmetically severe deformity, etc.

\subsubsection{Surgical treatment}

Although surgical resection provides the only complete curable option, it is rarely indicated because of the extensive nature and high morbidity and recurrence of CVMs. Complete resection is limited to superficially isolated lesions without invasion into deeper structures, such as muscle, nerve, and bone. Incomplete resection of the nidus or ligation of the feeding artery without removal of the nidus may result in the faster growth of quiescent malformations (Kim et al., 2006). Therefore, only selective cases have been recommended for surgical removal.

If a surgical resection is planned, preoperative embolization using ethanol, ethanolamine oleate, or N-butyl cyanoacrylate (NBCA) helps to delineate the extent of surgery and reduce intra-operative bleeding.

In conclusion, surgical approach for CVM should be considered carefully and planned perfectly because it has a potential to exacerbate the manifestations of CVM, as well greatly increasing risk for complications and recurrence.

\subsubsection{Endovascular treatment}

As previously described, surgical intervention for most CVMs is not an option due to location and infiltrative nature. The new concepts of "endovascular treatment" to treat CVMs or to control symptoms have been developed by the multidisciplinary team approach. Endovascular treatment, composed of embolization and sclerotherapy, is now well accepted as an effective treatment modality for CVMs, the diffuse type of extratruncular form in particular.

Several sclerosing agents have been used in the clinical setting. First, absolute ethanol is the most effective sclerosing agent to treat the CVM itself or to control the secondary consequences caused by the CVM. Ethanol can be delivered by an endovascular approach or administered by a direct puncture technique (Figure 5). However, acute caution is required when the ethanol is delivered into circulatory system via malformed vessels. The ethanol increases pulmonary arterial pressure and can, in the worst case, cause a pulmonary artery spasm and subsequent cardiopulmonary arrest. In addition, it can directly damage the surrounding tissues, including skin, soft tissue, nerve, tendon, muscle, and bone, and cause 
cosmetic problems and functional complications. Therefore, close monitoring of the cardiopulmonary system, including the pulmonary artery wedge pressure, is absolutely necessary during and immediately after the embolo/sclerotherapy. Embolo/sclerotherapy using ethanol should be performed only when the therapeutic benefits are considered to outweigh the risks.
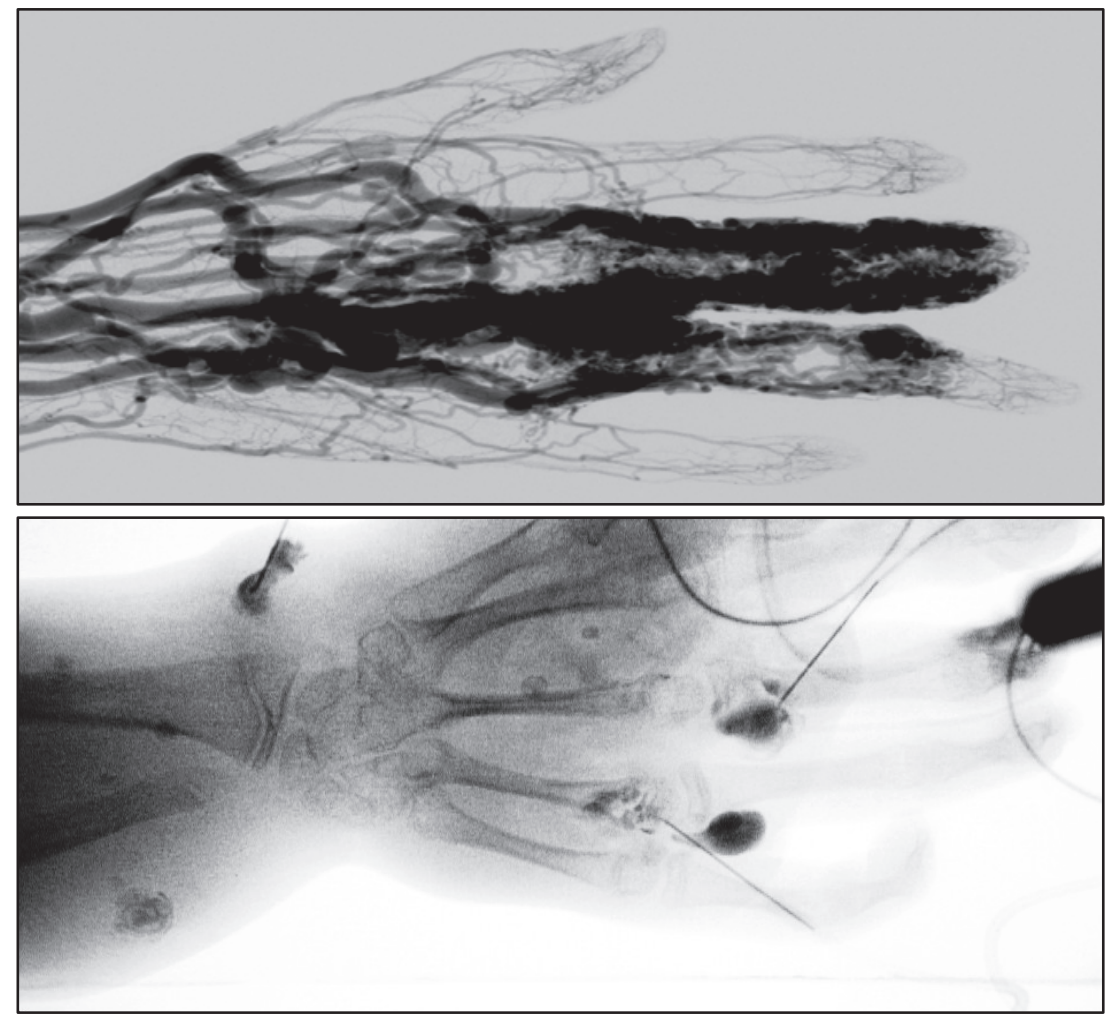

Fig. 5. Embolo/sclerotherapy by direct puncture technique in patient with arteriovenous malformation in the hand.

NBCA as an independent agent is not an ideal treatment for the diffuse and infiltrative types of CVM, but preoperative NBCA embolo/sclerotherapy assists in hemorrhage minimization during the surgical excision of CVM. Safer alternative agents, such as ethanolamine, polidocanol, and sodium tetradecyl sulfate, are currently being used and assessed in the control of CVM symptoms, particularly venous malformation

\section{Congenital vascular malformations: Skin and soft tissue injuries}

Embolo/scleotherapy may be an effective treatment modality for most CVMs, especially the diffuse infiltrating type of extratruncular CVM, due to the low recurrence and acceptable morbidity. Thus, the embolo/sclerotherapy is the main strategy utilized to treat the CVM itself and control secondary symptoms when complete surgical excision is not a viable option. 
However, few reports exist for the incidence and treatment of skin and soft tissue injuries developed after embolo/sclerotherapy in patients with CVMs. In addition, it is unknown which types of CVMs are more susceptible to skin and soft tissue injuries and which treatment methods are the most successful for these injuries.

We previously reported the incidence of skin and soft tissue injury after embolo/scleorotherapy for CVM and reviewed the prognosis according to the treatment modalities in patients with skin and soft tissue injuries (Lee et al., 2008). This chapter, based on our study, has described the outcomes according to treatment methods in patients with skin and soft tissue injuries developed after embolo/sclerotherapy.

\subsection{Incidence}

A retrospective review of 1,823 patients with a CVM, 573 of whom were managed by a multidisciplinary approach of embolo/sclerotherapy, was performed. Absolute or $80 \%$ ethanol, ethanolamine oleate, NBCA, or various types of coils or contour particles were used as the embolo/sclerosing agents based on the location, the severity, and the extent of the CVM.

Our study indicated that skin and soft tissue injuries occurred in $11.9 \%$ of patients $(n=68)$. Yun et al. (2009) also demonstrated that the incidence of skin necrosis after percutaneous ethanol sclerotherapy in venous malformations was $8 \%$. However, Jin et al. (2008) reported that only 6 sessions of tissue necrosis (1\%) among 592 sclerotherapy sessions. The necrosis developed in the finger tips after 5 treatment sessions and in the chin area after 1 treatment session. They reported that all lesions were spontaneously healed. We thought that lower incidence of tissue necrosis was due to ethanol usage only for sclerosis of the draining vein of venous malformations.

In our study, skin and soft tissue injuries occurred in $15.6 \%$ of those that used ethanol, in $6.3 \%$ of those that used ethanolamine oleate, and in $8.3 \%$ of those that used glue (Lee et al., 2008). The incidence of skin and soft tissue injuries after embolo/sclerotherapy according to the Hamburg classification is described in Table 2.

First of all, our study indicated there were no skin and soft tissue injuries in patients with the truncular forms of CVMs (Lee et al., 2008). Moreover, embolo/sclerotherapy for extratruncular forms of arterial and lymphatic malformations did not lead to skin and soft tissue injuries. In addition, embolo/sclerotherapy in patients with extratruncular type of arteriovenous shunting types was correlated with the largest portion of skin and soft tissue injuries $(n=42 / 142)$ and these injuries showed similar rates for both the infiltrating and the limited types (30.6\% vs. $26.7 \%)$. Skin and soft tissue injuries were more common in the infiltrating type than in the limited type of the extratruncular form (13.2\% vs. $9.7 \%)$ of the CVMs. Based on the location of the CVMs, the incidence of skin and soft tissue injuries was $20.4 \%$ in the upper extremities, $14.3 \%$ in the lower extremities and the perineum/genitalia, $9.1 \%$ in the pelvis, $7.5 \%$ in the head and neck, and $6.4 \%$ in the thorax. Among all skin and soft tissue injuries, only one occurred in a patient with a venous malformation which involved the tongue and lip.

In conclusion, our study suggested that the extratruncular form of arteriovenous shunting malformation and the extratruncular form of venous malformation were more susceptible to skin and soft tissue injuries after embolo/sclerotherapy in patients with CVMs. 


\begin{tabular}{|c|c|c|}
\hline $\begin{array}{l}\text { Types of CVM } \\
\quad(n=573)\end{array}$ & $\begin{array}{l}\text { Forms of CVM } \\
\quad(n=573)\end{array}$ & $\begin{array}{l}\text { Skin and soft tissue injuries } \\
(n=68)\end{array}$ \\
\hline \multirow[t]{4}{*}{ Arterial $(n=1)$} & Truncular $(\mathrm{n}=0)$ & $0(0 \%)$ \\
\hline & Extratruncular $(\mathrm{n}=1)$ & $0(0 \%)$ \\
\hline & Limited (n=1) & \\
\hline & Infiltrating $(\mathrm{n}=0)$ & \\
\hline \multirow[t]{4}{*}{ Venous $(n=273)$} & Truncular $(n=1)$ & $0(0 \%)$ \\
\hline & Extratruncular $(\mathrm{n}=272)$ & $22(32.4 \%)$ \\
\hline & Limited $(\mathrm{n}=57)$ & 6 \\
\hline & Infiltrating $(n=215)$ & 16 \\
\hline \multirow[t]{4}{*}{ Lymphatic (n=102) } & Truncular $(n=4)$ & $0(0 \%)$ \\
\hline & Extratruncular $(\mathrm{n}=98)$ & $0(0 \%)$ \\
\hline & Limited $(\mathrm{n}=80)$ & \\
\hline & Infiltrating $(\mathrm{n}=18)$ & \\
\hline \multirow[t]{4}{*}{ AV shunting $(n=143)$} & Truncular $(\mathrm{n}=1)$ & $0(0 \%)$ \\
\hline & Extratruncular $(\mathrm{n}=142)$ & $42(61.8 \%)$ \\
\hline & Limited $(n=45)$ & 12 \\
\hline & Infiltrating ( $\mathrm{n}=97$ ) & 30 \\
\hline \multirow[t]{4}{*}{ Combined $(n=54)$} & Truncular $(\mathrm{n}=1)$ & $0(0 \%)$ \\
\hline & Extratruncualr $(n=53)$ & $4(5.9 \%)$ \\
\hline & Limited $(\mathrm{n}=13)$ & 1 \\
\hline & Infiltrating $(\mathrm{n}=40)$ & 3 \\
\hline
\end{tabular}

Table 2. Patients with skin and soft tissue injuries after embolo/sclerotherapy according to Hamburg classification in patients with congenital vascular malformations. (CVM, congenital vascular malformation; $\mathrm{AV}$, arteriovenous)

\subsection{Treatment and outcome}

The treatment strategy for skin and soft tissue injuries was developed after embolo/sclerotherapy was decided by multidisciplinary team and was determined by the extent, the depth, and the severity of the injury. First, conservative management such as a simple dressing was applied, but the infected wound was managed by antibiotics, surgical debridement, and drainage. If the eschar led to the contracture, then escharectomy has been performed to relieve the contracture and recover the joint motion. The skin and soft tissue injuries did not heal with conservative management or those that involved deeper structures, such as muscles or tendons, have subsequently required plastic reconstructive surgery. In the extremities, severe injuries with extensive necrosis in deeper tissue, severe deformity or pain, or functional disabilities were amputated (Figure 6).

As a result, 40 of 68 patients (58.8\%) with skin and soft tissue injuries have been healed by conservative management and 18 escharectomies (26.5\%) and 4 amputations (5.9\%) were performed (Lee et al., 2008). As a result of embolo/sclerotherapy, all patients who needed amputation had the infiltrating arteriovenous shunting extratruncular type. 

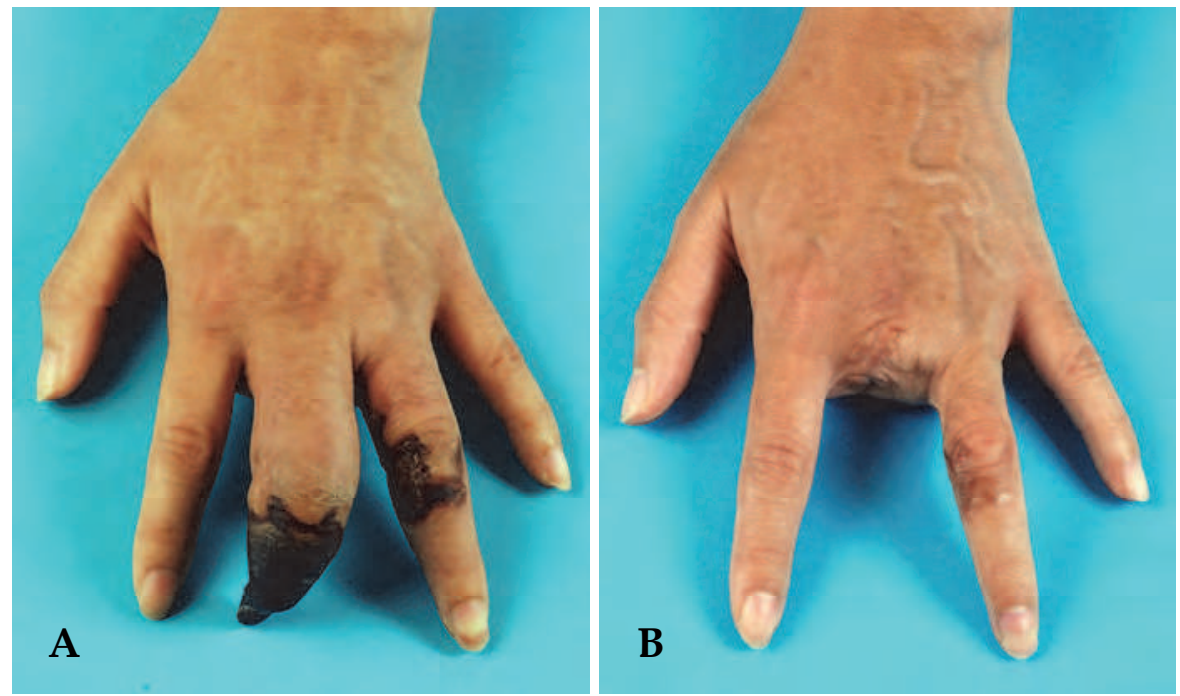

Fig. 6. A, Necrosis of $3^{\text {rd }}$ fingertip after embolo/sclerotherapy in patient with arteriovenous malformation. B, After 3rd finger amputation.

In our study, plastic reconstructive surgeries, including split-thickness or full-thickness skin grafts, were performed in 6 of 68 patients $(8.8 \%)$ with skin and soft tissue injuries (Lee et al., 2008). The characteristics of the patients who underwent skin grafts and the clinical outcomes are described in Table 3.

\begin{tabular}{|c|c|c|c|c|c|c|}
\hline No. & Type of CVM & $\begin{array}{c}\text { Form of } \\
\text { CVM }\end{array}$ & $\begin{array}{c}\text { Type of } \\
\text { sclerosant }(\mathrm{ml})\end{array}$ & $\begin{array}{l}\text { Location } \\
\text { of injury }\end{array}$ & $\begin{array}{c}\text { Method of } \\
\text { skin graft }\end{array}$ & Outcome \\
\hline$\overline{1}$ & AV shunting & ET & Pure ethanol(12) & Ear & FTSG & Completely healed \\
\hline 2 & AV shunting & ET & $\begin{array}{l}\text { Pure } \\
\text { ethanol(40.5) }\end{array}$ & Knee & STSG & Completely healed \\
\hline 3 & AV shunting & ET & $\begin{array}{l}\text { Pure } \\
\text { ethanol(6.75) }\end{array}$ & Hand & STSG & Completely healed \\
\hline 4 & AV shunting & ET & NBCA(12) & Occiput & STSG & Completely healed \\
\hline 5 & Venous & ET & Pure ethanol(18) & Arm & STSG & Completely healed \\
\hline 6 & Venous & ET & $\begin{array}{l}\text { Pure } \\
\text { ethanol(20.5) }\end{array}$ & Arm & STSG & Completely healed \\
\hline
\end{tabular}

Table 3. The characteristics and the outcome for 6 skin and soft tissue injuries that were performed skin graft. (CVM, congenital vascular malformation; AV, arteriovenous; ET, extratruncular; NBCA, N-butyl cyanoacrylate; FTSG, full-thickness skin graft; STSG, splitthickness skin graft)

Two plastic surgeries were performed in the injuries that developed as a result of embolo/sclerotherapy for the infiltrating venous extratruncular types, 1 for the limited arteriovenous extratruncular type, 3 for the infiltrating arteriovenous shunting extratruncular type. All plastic reconstructive surgeries were performed only if the injured wound had not healed with conservative management or involved deeper structures and all skin grafts could be successfully performed (Figure 7). 


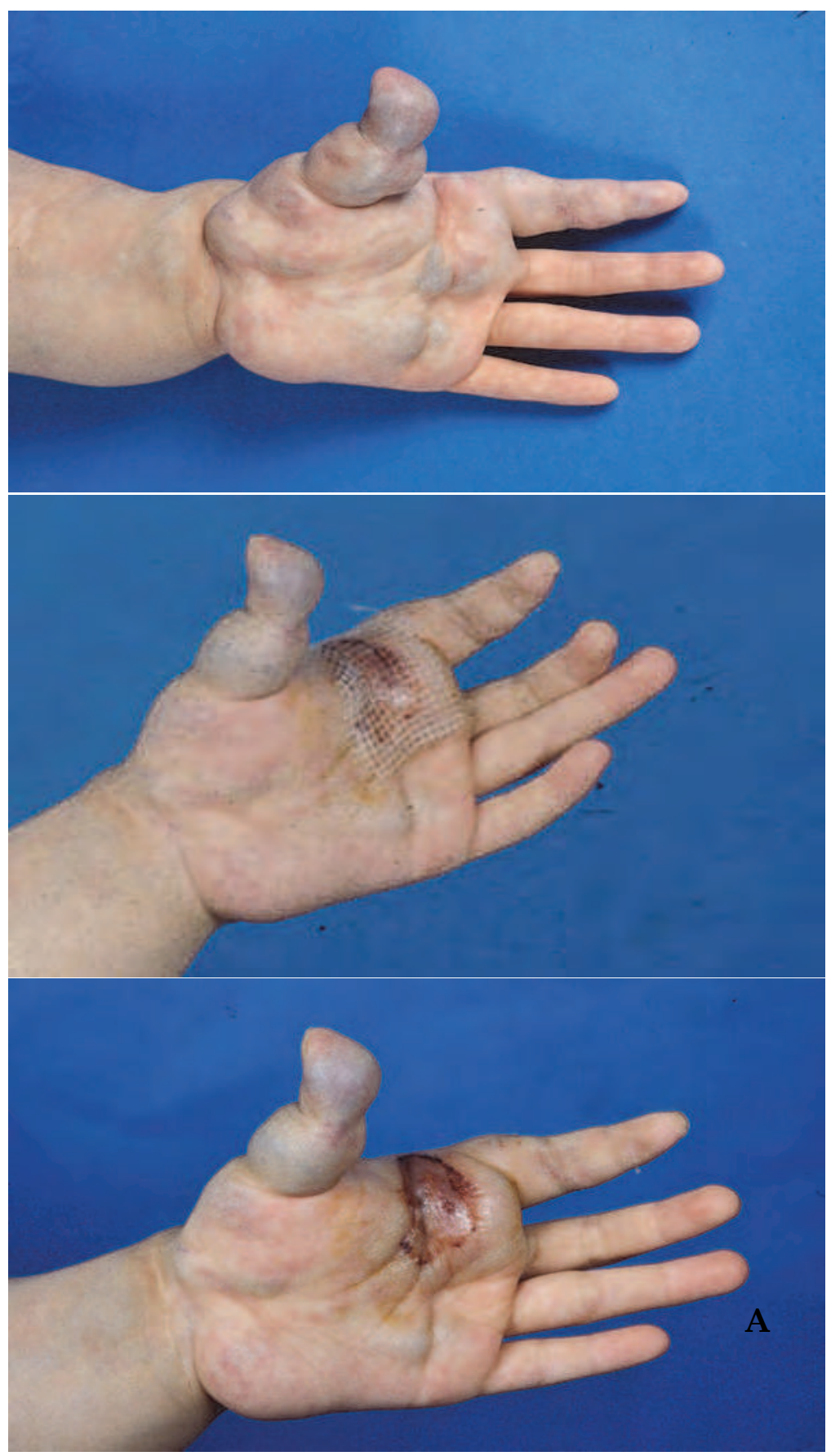




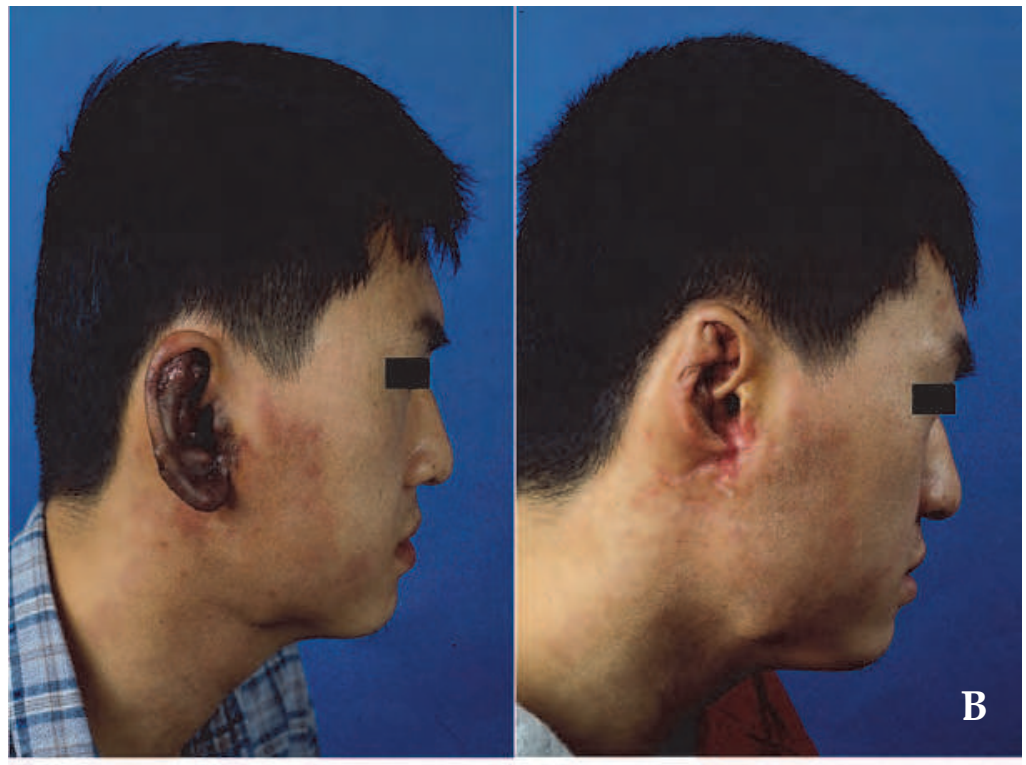

Fig. 7. A, Split-thickness skin graft in patient with skin and soft tissue injury in the palm after pure ethanol embolo/sclerotherapy. B, Full-thickness skin graft in patient with necrosis of the ear after pure ethanol embolo/sclerotherapy.

\section{Conclusions}

CVMs are relatively uncommon congenital anomalies and difficult to be distinguished from other vascular conditions, such as a simple birthmark or a hemangioma. In addition, the CVMs show numerous clinical manifestations according to the involved vascular system, the location, and the extent, and additionally require variable clinical responses depending on the manifestation.

Although much effort has been made to accurately diagnose and completely treat CVMs, they still remain challenging even to a specialist. Therefore, a multidisciplinary team composed of specialists from many surgical and clinical disciplines is absolutely needed to develop a successful strategy for the treatment modality and management of complications after treatment.

As a current treatment method for CVMs, embolo/sclerotherapy has become a mainstay because in most CVMs it is impossible to completely remove the nidus. Even if embolo/sclerotherapy has been proven a relatively safe and effective treatment modality in most patients with CVM, our study indicated that skin and soft tissue injuries occurred with relatively high frequency in patients undergoing embolo/sclerotherapy. In particular, our results suggested that the extratruncular forms of the arteriovenous shunting malformation and the venous malformation require acute vigilance for signs of skin and soft tissue injuries in patients undergoing embolo/sclerotherapy, even though most injuries were completely healed with conservative management.

Additionally, skin grafts may be the best treatment option for most skin and soft tissue injuries unable to be healed by conservative management or involved beyond the muscle layer after embolo/sclerotherapy in patients with CVMs. 


\section{Acknowledgment}

We gratefully appreciate the efforts of Byung-Boong Lee, M.D., PhD, FACS, who established the Congenital Vascular Malformation Clinic in Samsung Medical Center. In addition, we specially thank to Na-Ri Kim, RN, APN and Shin-Young Woo, RN for collecting and organizing the data of the patients with CVMs.

\section{References}

Arneja, JS. \& Gosain, AK. (2008) Vascular malformations. Plast Reconstr Surg., Vol.121, No.4, pp. 195e-206e, ISSN 0032-1052

Bastide G. \& Lefebvre D. (1989) Anatomy and organogenesis and vascular malformations. In: Vascular Malformations, Belov S, Loose DA, Weber J, ed., pp. 20-22, EinhornPresse Verlag $\mathrm{GmbH}$, Reinbek, Germany

Belov S. (1989) Classification, terminology, and nosology of congenital vascular defects. In: Vascular Malformations, Belov S, Loose DA, Weber J, ed., pp 25-30, Einhorn-Presse, Reinbek, Germany

Belov S. (1990) Classification of congenital vascular defects. Int Angiol., Vol.9, No.3, pp. 141146, ISSN 1061-1711

Jin Y.; Lin X; Li W.; Hu X.; Ma G. \& Wang W. (2008) Sclerotherapy after embolization of draining vein: a safe treatment method for venous malformations. J Vasc Surg., Vol.47, No.6, pp. 1292-1299, ISSN 0741-5214

Kim JY.; Kim DI.; Do YS.; Lee BB.; Kim YW.; Shin SW.; Byun HS.; Roh HG.; Choo IW.; Hyon WS.; Shim JS. \& Choi JY. (2006) Surgical treatment for congenital arteriovenous malformation: 10 years' experience. Eur J Vasc Endovasc Surg., Vol.32, No.1, pp. 101106, ISSN 1078-5884

Lee BB. (2005) New approaches to the treatment of congenital vascular malformations (CVMs)--a single centre experience. Eur J Vasc Endovasc Surg., Vol.30, No.2, pp. 184197, ISSN 1078-5884

Lee BB.; Laredo J.; Lee TS.; Huh S. \& Neville R. (2007) Terminology and classification of congenital vascular malformations. Phlebology, Vol.22, No.6, pp. 249-252, ISSN 02683555

Lee KB.; Kim DI.; Oh SK.; Do YS.; Kim KH. \& Kim YW. (2008) Incidence of soft tissue injury and neuropathy after embolo/sclerotherapy for congenital vascular malformation. J Vasc Surg., Vol.48, No.5, pp. 1286-1291 ISSN 0741-5214

Malan E. \& Puglionisi A. (1965) Congenital angiodysplasias of the extremities, note II: arterial, arterial and venous, and hemolymphatic dysplasias. J Cardiovasc Surg (Torino)., Vol.6, No.4, pp. 255-345, ISSN 0021-9509

Mulliken JB. (1993) Cutaneous vascular anomalies. Semin Vasc Surg., Vol.6, No.4, pp. 204218, ISSN 0895-7967

Mulliken JB. \& Glowacki J. (1982) Hemangiomas and vascular malformations in infants and children: a classification based on endothelial characteristics. Plast Reconstr Surg., Vol.69, No.3, pp. 412-420, ISSN 0032-1052

Yun WS.; Kim YW.; Lee KB.; Kim DI.; Park KB.; Kim KH.; Do YS. \& Lee BB. (2009) Predictors of response to percutaneous ethanol sclerotherapy (PES) in patients with venous malformations: analysis of patient self-assessment and imaging. J Vasc Surg., Vol.50, No.3, pp. 581-589, ISSN 0741-5214

Villavicencio JL.; Scultetus A. \& Lee BB. (2002) Congenital vascular malformations: when and how to treat them. Semin Vasc Surg., Vol.15, No.1, pp. 65-71, ISSN 0895-7967 


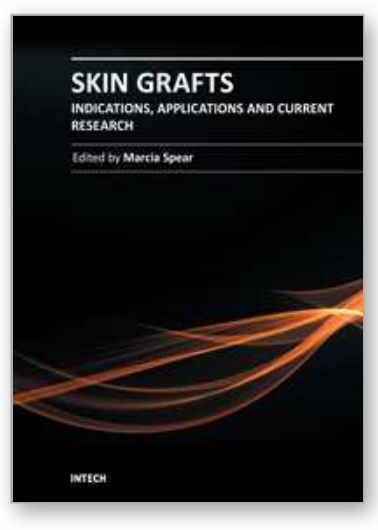

\author{
Skin Grafts - Indications, Applications and Current Research \\ Edited by Dr. Marcia Spear
}

ISBN 978-953-307-509-9

Hard cover, 368 pages

Publisher InTech

Published online 29, August, 2011

Published in print edition August, 2011

The procedure of skin grafting has been performed since 3000BC and with the aid of modern technology has evolved through the years. While the development of new techniques and devices has significantly improved the functional as well as the aesthetic results from skin grafting, the fundamentals of skin grafting have remained the same, a healthy vascular granulating wound bed free of infection. Adherence to the recipient bed is the most important factor in skin graft survival and research continues introducing new techniques that promote this process. Biological and synthetic skin substitutes have also provided better treatment options as well as HLA tissue typing and the use of growth factors. Even today, skin grafts remain the most common and least invasive procedure for the closure of soft tissue defects but the quest for perfection continues.

\title{
How to reference
}

In order to correctly reference this scholarly work, feel free to copy and paste the following:

Kyung-Bok Lee and Dong-Ik Kim (2011). Skin and Soft Tissue Injuries in Congenital Vascular Malformations, Skin Grafts - Indications, Applications and Current Research, Dr. Marcia Spear (Ed.), ISBN: 978-953-307-5099, InTech, Available from: http://www.intechopen.com/books/skin-grafts-indications-applications-and-currentresearch/skin-and-soft-tissue-injuries-in-congenital-vascular-malformations

\section{INTECH}

open science | open minds

\section{InTech Europe}

University Campus STeP Ri

Slavka Krautzeka 83/A

51000 Rijeka, Croatia

Phone: +385 (51) 770447

Fax: +385 (51) 686166

www.intechopen.com

\section{InTech China}

Unit 405, Office Block, Hotel Equatorial Shanghai

No.65, Yan An Road (West), Shanghai, 200040, China

中国上海市延安西路65号上海国际贵都大饭店办公楼405单元

Phone: +86-21-62489820

Fax: $+86-21-62489821$ 
(C) 2011 The Author(s). Licensee IntechOpen. This chapter is distributed under the terms of the Creative Commons Attribution-NonCommercialShareAlike-3.0 License, which permits use, distribution and reproduction for non-commercial purposes, provided the original is properly cited and derivative works building on this content are distributed under the same license. 